\title{
Turismo e pedestrianismo: reflexões acerca da Via Algarviana/Portugal
}

\section{Tourism and trekking: reflections on Via Algarviana/Portugal}

\author{
Jean Carlos Vieira Santos (SANTOS, J. C. V.) ${ }^{*}$, \\ Wilton de Araújo Medeiros (MEDEIROS, W. de A.) ${ }^{* *}$ e \\ Vinicius Polzin Druciaki (DRUCIAKI, V. P.)
}

RESUMO - No presente artigo se aborda o pedestrianismo como oferta complementar aos produtos "turismo e sensibilização ecológica e cultural" no destino turístico internacional Algarve, sul de Portugal, num projeto desenvolvido pela Associação de Defesa do Patrimônio Cultural e Ambiental do Algarve (ALMARGEM). Esse trabalho tem assumido relevância nas primeiras décadas do século XXI, no contexto do destino turístico e da cidade de Loulé (Portugal), sede da referida Organização Não Governamental (ONG). A experiência tem como chave interpretativa o desdobramento das reflexões acerca da inovação estratégica do produto "pedestrianismo", praticado no percurso denominado Via Algarviana. Esta é uma rota pedestre que liga a cidade de Alcoutim ao Cabo de São Vicente (Vila do Bispo), com extensão de $300 \mathrm{~km}$ - tal aspecto é resultado de uma investigação de fontes escritas, orais e de páginas da internet. Ademais, há uma análise teórica do turismo na conjuntura da sustentabilidade, a partir da obra portuguesa "Compêndio de Economia Regional" (SILVA; PERNA, 2005).

Palavras-chave: Turismo; Via Algarviana; Pedestrianismo; Destino Algarve; Portugal.

ABSTRACT - This article discusses trekking as a complementary offer to the products "tourism and environmental and cultural awareness" in the international tourist destination Algarve, southern Portugal, in a project developed by Associação de Defesa do Patrimônio Cultural e Ambiental do Algarve (ALMARGEM). This work has assumed relevance in the early decades of the $21^{\text {st }}$ century, in the context of tourist destination and the city of Loulé (Portugal), host of the referred Non-Governmental

\footnotetext{
* Formação: Graduação, Mestrado e Doutorado em Geografia pela Universidade Federal de Uberlândia (UFU) e Pós-doutorado em Turismo pela Universidade do Algarve (Portugal). Atividade profissional: Professor e Bolsista BIP (PrP) da Universidade Estadual de Goiás (UEG) - Campus Caldas Novas. Membro voluntário da Associação de Defesa do Patrimônio Cultural e Ambiental do Algarve (ALMARGEM), de Portugal. Endereço físico para correspondência: Rua Santo André, 58, ap. 103. CEP: 75690-000 - Caldas Novas - Goiás - Brasil. E-mail: svcjean@yahoo.com.br

** Formação: Graduação em Arquitetura e Urbanismo pela Pontifícia Universidade Católica de Goiás (PUC-Goiás), Mestrado em Gestão do Patrimônio Cultural (PUC-Goiás), Doutorado em História pela Universidade Federal de Goiás (UFG). Atividade profissional: Professor Doutor do Curso de Mestrado em Ensino de Ciências e do Curso de Graduação em Arquitetura e Urbanismo da Universidade Estadual de Goiás (UEG) - Campus Anápolis. Endereço físico para correspondência: Rua K, quadra 13, lote 19, ap. 301, Cidade Jardim. CEP: 75080-560 - Anápolis - Goiás - Brasil. E-mail: wilton_68@ hotmail.com

*** Formação: Graduação em Geografia pela Universidade Estadual do Centro-Oeste (UNICENTRO), Mestrado em Geografia pela Universidade Estadual de Maringá (UEM), Doutorado em Geografia pela Universidade Estadual Paulista Júlio de Mesquita Filho (UNESP). Atividade profissional: Professor Doutor do Curso de Graduação em Geografia da UEG - Campus Cora Coralina. Endereço físico para correspondência: Rua 259, 38, ap. 2208. CEP: 74610-230 - Goiânia - Goiás - Brasil. E-mail: geomobilidade@gmail.com
} 
Organization (NGO). The experience has the unfolding of reflections on strategic innovation of the product "trekking" as an interpretative key, practiced in the trajectory named as Via Algarviana. This is a pedestrian route linking the city of Alcoutim to Cabo de São Vicente (Vila do Bispo), with a length of 186 miles $(300 \mathrm{~km})$ - this aspect is a result of an investigation of written, oral sources and websites. Furthermore, there is a theoretical analysis of tourism in the conjuncture of sustainability, from the Portuguese work "Compêndio da Economia Regional” (SILVA, PERNA, 2005).

Key words: Tourism; Via Algarviana; Trekking; Algarve destination; Portugal. 


\section{INTRODUÇÃO}

O pedestrianismo, como oferta complementar aos produtos "turismo e sensibilização ecológica e cultural" em diferentes paisagens, é um projeto que tem como grande parceira a Associação de Defesa do Patrimônio Cultural e Ambiental do Algarve (ALMARGEM). Esse trabalho tem assumido relevância nas primeiras décadas do século XXI, sobretudo na região Algarve e na cidade turística de Loulé (Portugal), sede da referida Organização Não Governamental (ONG) (ALMARGEM, 2016).

A Almargem (2016) desenvolve habitualmente atividades diversificadas, desde a execução de projetos de sensibilização ecológica e cultural até a organização de ações de descoberta e promoção da natureza e do mundo rural. São ações realizadas numa lógica de visitação a territórios e paisagens, de arranjos de antigos espaços públicos, de valorização e requalificação de tradicionais zonas rurais e urbanas.

No presente artigo se aborda uma experiência que tem como chave interpretativa o desdobramento das reflexões e interpretações acerca da inovação estratégica do produto "pedestrianismo", praticada no percurso denominado Via Algarviana. Essa é uma rota pedestre que liga a cidade de Alcoutim (FIGURA 1) ao Cabo de São Vicente (Vila do Bispo), com extensão de $300 \mathrm{~km}$.

O itinerário engloba os municípios Alcoutim, Aljezur, Castro Marim, Tavira, São Brás de Alportel, Loulé, Silves, Monchique, Lagos, Portimão e Vila do Bispo, todos na região Algarve (MAPA 1), sul de Portugal. A Via Algarviana pode ser considerada a "espinha-dorsal" de uma rede de percursos pedestres, com traçados divulgados e identificados no terreno. 


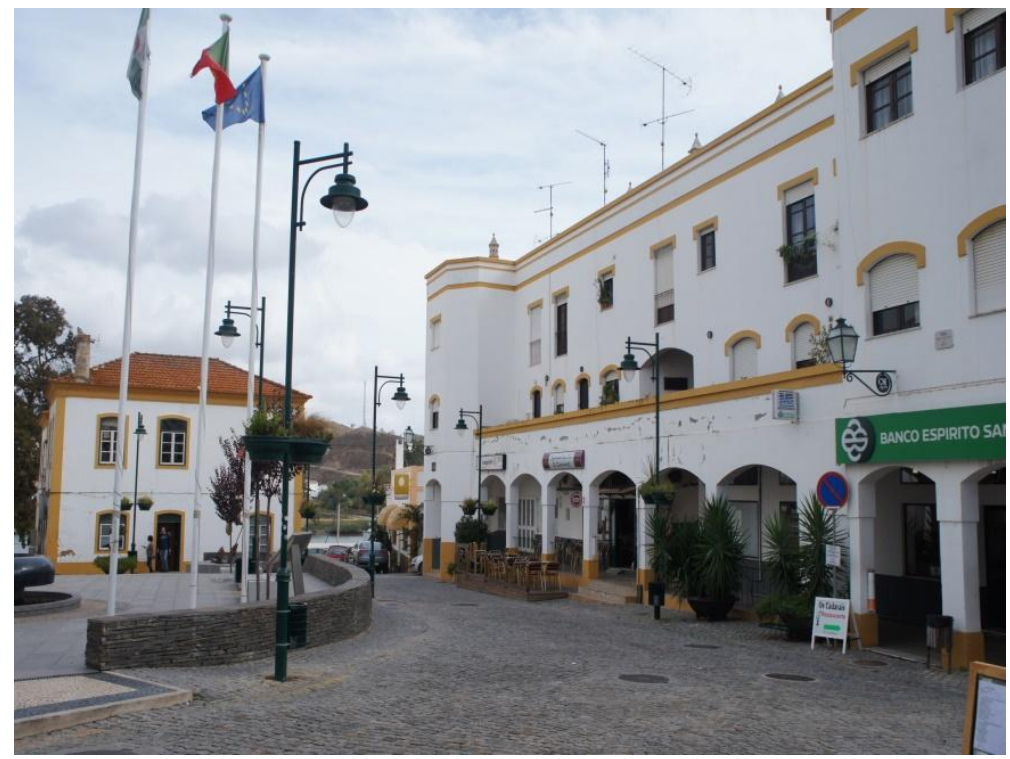

FIGURA 1 - CENTRO DA CIDADE DE ALCOUTIM, ÀS MARGENS DO RIO GUADIANA, NA FRONTEIRA COM A ESPANHA.

FONTE: Jean Carlos Vieira Santos, 2014.

MAPA 1 - MUNICÍPIOS DA REGIÃO ALGARVE.

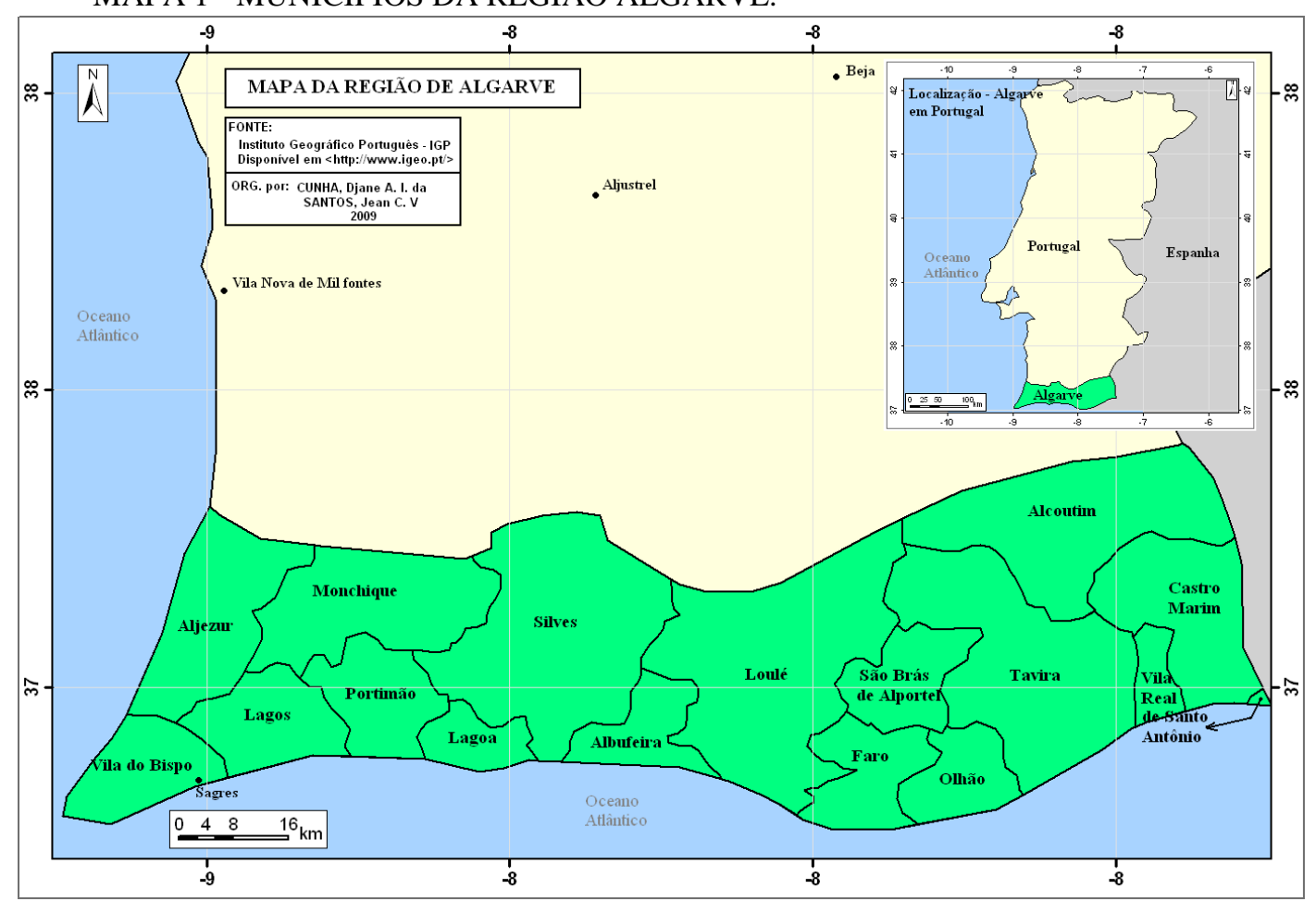

FONTE: Instituto Geográfico Português - IGP (2009). Disponível em: www.igeo.pt.

Cumpre destacar que a Almargem é uma associação sem fins lucrativos que trabalha na perspectiva de valorização, identificação, contextualização e reinvenção da arte de caminhar em grupos organizados com uma componente associada ao turismo 
(ALMARGEM, 2016). Desse modo, o encadeamento geográfico deste trabalho tem como escala de análise a cidade de Loulé e a região Algarve.

Nesse viés, Ribeiro (1986), um especialista dedicado ao estudo geográfico português, caracteriza a paisagem algarvia por meio da tradição árabe, ao salientar que esses povos reforçaram o tom mediterrâneo regional e historicamente foram mais polidos. Outra concepção a assinalar diz respeito ao fato de, na referida região, haver cidades com arquiteturas, monumentos e vestígios de romanos, visigóticos e árabes. Santos (2013, p. 105) afirma que os árabes foram “[...] os responsáveis pelo nome regional Algarve, cuja denominação Al-Gharb significa Ocidente".

Sob essa nuance, não interessa aqui a descrição dos caminhos pedestres da região Algarve, mas a discussão acerca da relação entre pedestrianismo e sustentabilidade, com uma abordagem integrada nas tendências da atividade turística, com sensibilizações ecológicas e culturais. Desse modo, será sublinhado o trabalho da Almargem presente em toda a Via Algarviana na região Algarve, um projeto para visitantes interessados nos territórios de baixa densidade turística do sul de Portugal. Essa visão inovadora oferece oportunidades profissionais e novos atendimentos à cadeia do turismo.

É, porquanto, uma componente complementar não só aos produtos "turismo e sensibilização ecológica e cultural", mas também ao produto "sol e praia", que é a principal oferta do destino turístico internacional Algarve (SANTOS; SILVA, 2015). Em estudos sobre economia e meio ambiente, o turismo tem sido colocado como uma extensão de outras atividades turísticas (pedestrianismo, pequenos meios de hospedagem e alimentação, por exemplo) e uma economia de experiências em que territórios ecológicos e culturais se tornam um instrumento de oportunidade e desenvolvimento.

Diante do objetivo apresentado, deve-se fazer, ainda nesse ponto, uma breve referência a Silva e Perna (2005). Segundo esses autores, o turismo é um fenômeno espacial cujo desenvolvimento sustentável exige atuações multidisciplinares sobre variáveis econômicas, sociais, ambientais e institucionais.

Quaisquer que sejam os agentes e o estado/opções de desenvolvimento turístico do território, a via para o desenvolvimento e a qualidade de vida passa obrigatoriamente pela “[...] conservação e valorização dos recursos endógenos, os quais, por sua vez, 
constituem-se como fundamentais na produção e repartição de riqueza, criação de emprego e valorização do destino" (SILVA; PERNA, 2005, p. 453).

Nesses termos, pode-se dizer, de acordo com Tovar e Carvalho (2011), que há tempos o ser humano se realiza espiritualmente na prática do pedestrianismo. $\mathrm{O}$ homem, por natureza e analisado em termos genéricos, é um pedestre, um sujeito que procura caminhar em suas viagens, dada a capacidade que possui de se adaptar a territórios, paisagens e lugares visitados. Além disso, possui imaginação, gosto e interesse por percorrer espaços que não fazem parte de seu cotidiano. Utiliza-se para designar as deslocações a pé:

Expressões, em português, como caminhar, andar a pé, praticar pedestrianismo, ou walking, hiking (EUA) ou rambling (Reino Unido), em inglês, encontram-se na literatura e referem-se todas à mesma actividade de andar a pé, em trilhos sinalizados ou promovidos para esse fim. A palavra trekking, também é associada à mesma atividade [...]. (TOVAR; CARVALHO, 2011, p. 306).

O turista pedestre é um tipo de visitante cada vez mais culto, atento, observador e interessado pelas questões ambientais e culturais, que acredita nas práticas que contribuam para um mundo melhor e é um consumidor de produtos que compensam seus gastos e efeitos ao meio ambiente. Contudo, essa discussão necessita não somente de entendimento das ações desenvolvidas pela Almargem, mas também de uma abordagem teórica sobre a complexidade e as densidades inerentes ao turismo e à sustentabilidade.

Portanto, neste artigo se trazem argumentos preliminares a favor da abordagem turismo/pedestrianismo e do desafio da sustentabilidade/qualidade de vida, considerando que há importantes traços e instrumentos a serviço do desenvolvimento regional, nomeadamente a partir da promoção de um turismo não massificado.

É possível afirmar, a partir da experiência algarvia, que o turista pedestre é um visitante que participa ativamente das ações ligadas ao meio ambiente e à cultura, mostrando seu respeito com a sociedade acolhedora. É um viajante que se preocupa com a preservação dos recursos naturais e culturais, o cuidado com a saúde e qualidade de vida.

Vale ressaltar que este artigo é também resultado de uma investigação de fontes escritas, orais e de páginas da internet. Uma ordem indispensável para a construção do 
trabalho se refere às fontes escritas ou à pesquisa documental (levantamento das referências), recorrendo, especialmente, aos serviços da biblioteca da Universidade do Algarve.

Essa etapa foi fundamental para a construção teórica; no entanto, constatou-se uma relativa escassez de obras no domínio do pedestrianismo, além dessa temática conexa ao desenvolvimento econômico do turismo e aos patrimônios ambiental e cultural regional. Tem-se em vista que, para reduzir a lacuna teórica encontrada, foram fundamentais os trabalhos de campo na sede da Almargem, na cidade de Loulé.

\section{O TURISMO NO CONTEXTO DA SUSTENTABILIDADE: UMA ABORDAGEM A PARTIR DA OBRA PORTUGUESA "COMPÊNDIO DE ECONOMIA REGIONAL"}

Cabe destacar inicialmente que, quando se pensa no desenvolvimento de atividades ligadas ao turismo e lazer, o desafio da sustentabilidade é maximizado pela sua íntima relação com os recursos naturais, “[...] cuja conservação é condição necessária para a prossecução de uma relação positiva entre a economia e a ecologia, da qual depende a evolução do próprio setor" (SILVA; PERNA, 2005, p. 449).

De acordo com os autores da mesma fonte acima, o patrimônio natural bem valorizado é um trunfo considerável, sobre o qual as ações de promoção turística insistem com frequência. Este é o paradoxo do turismo: quanto mais bem-sucedido for um local na oferta de um ambiente agradável para férias, mais visitantes atrairá e maior será o potencial de impactos negativos na qualidade ambiental do destino.

A resolução do paradoxo perpassa por atenuar a dependência entre os níveis de bem-estar provenientes da atividade turística e o consumo da natureza, isto é, pelos esforços de garantir mais bem-estar para todos em consonância com uma menor intensidade de uso dos recursos naturais. O turismo um setor estratégico do desenvolvimento das sociedades, concretizando "[...] fluxos de pessoas e bens que, a nível mundial e europeu, assume uma importância apenas ultrapassada por setores globalizados" (SILVA; PERNA, 2005, p. 449). 
$\mathrm{Na}$ efetivação da trajetória da sustentabilidade no turismo interagem quatro dimensões fundamentais. A ação simultânea é essencial, face aos objetivos de desenvolvimento sustentável, por oposição ao perigo de impulsos individualistas baseados em posições unidimensionais e conducentes, além de extremismos geradores a prazo de menos valias econômicas e/ou de externalidades negativas, com efeitos irreversíveis sobre o meio ambiente.

As dimensões econômicas e ambientais se unem à terceira dimensão social, assumida na Conferência das Nações Unidas sobre Ambiente e Desenvolvimento em 1992, no Rio de Janeiro (apud SILVA; PERNA, 2005). A quarta dimensão do desenvolvimento sustentável passa pelo envolvimento das instituições nesse objetivo global, com destaque para a Organização Mundial do Turismo que enfatiza a necessidade de integração entre a economia e o meio ambiente em todas as fases dos sistemas de produção e consumo. Isso foi sintetizado em um documento publicado em 1997, na Agenda 21, com o seguinte título: For the travel and tourism industry: towards environmental sustainable devellopment (apud SILVA; PERNA, 2005).

Segundo os autores citados, tal documento estabelece um programa de ação em que o setor do turismo se compromete a contribuir, nas suas áreas de competência, no tocante à realização das metas de desenvolvimento sustentável nos termos da Conferência do Rio de Janeiro. Nos instrumentos para a prossecução desse objetivo, três são considerados imprescindíveis pela referida organização, para a área de Travel \& Tourism:

Introdução ou fortalecimento de regulamentação de proteção ambiental e de saúde pública; uso dos mecanismos de livre mercado, pelos quais os preços dos bens e serviços devem refletir os custos dos recursos incorporados e dos outputs não comercializados; adoção voluntária pela indústria turística de programas, através dos quais assuma a responsabilidade e uma ética de gestão sobre produtos e processos, no sentido de uma máxima segurança e respeito pelo meio ambiente (SILVA; PERNA, 2005, p. 450-451).

A sustentabilidade se insere num plano multidimensional de melhoria do bemestar do turista e da comunidade receptora, de proteção e valorização do patrimônio e de promoção do crescimento e da competitividade das empresas. No entanto, a experiência demonstra que, "[...] sem planejamento e sem uma integração adequada do turismo com 
outras áreas estratégicas, poderão ocorrer sérios problemas ambientais e de sustentabilidade das atividades econômicas" (SILVA; PERNA, 2005, p. 451).

No que tange à dimensão ambiental, a avaliação da sustentabilidade turística deve se atentar aos seguintes critérios:

[...] renovação ambiental, quer pela vitalidade dos ecossistemas quer pela atratividade baseada no valor turístico dos recursos naturais; - prevenção, identificando as práticas compatíveis com os níveis de pressão e estado ambiental do território, bem como com outras atividades humanas; valorização, tendo presente que o valor atribuído ao ambiente de acordo com as identidades locais, consiste no meio de sensibilização mais eficaz e durável face à necessidade de inputs pelas atividades econômicas; - quadro de vida, por consideração da qualidade das relações sociais e bem-estar das populações residentes, face ao impacto do turismo (SILVA; PERNA, 2005, p. 466-467).

Vale lembrar que a Almargem busca promover a utilização sustentável dos recursos naturais e culturais ao longo da Via Algarviana. Com isso, garante-se a conservação dos territórios e das paisagens tradicionais que são espaços de baixa densidade populacional e de turistas ao sul de Portugal.

Pode-se afirmar que o projeto Via Algarviana é um elemento integrador dessa região e um eixo fundamental na construção de uma base econômica de cooperação entre os sujeitos sensibilizados com a atividade turística. Quanto à dimensão econômica, a análise da atividade turística, conforme o objetivo de desenvolvimento sustentável, deve considerar os seguintes critérios:

[...] rentabilidade, pelo desempenho da atividade, aferindo se este é capaz de remunerar o trabalho e os capitais investidos; - integração territorial, medida pelo grau de participação do turismo nos circuitos econômicos de emprego, investimentos, entre outros; - flexibilidade, tendo presente os perigos da monoespecialização e simultaneamente as desvantagens de um excesso de diversificação; - perenidade, pelo esforço de manutenção e renovação da atratividade do território (SILVA; PERNA, 2005, p. 467).

Nesse quadro teórico de análise, considera-se que o projeto Via Algarviana não só amplia a atração turística dos espaços de baixa densidade populacional, como traz também uma proposta de turismo alternativo por meio do pedestrianismo apoiado, sobretudo, pelos recursos de base local. Por sua vez, a quantificação da dimensão social do turismo autossustentável deve obedecer a critérios de avaliação assentados em: 
[...] reconhecimento, medindo o contributo do turismo para as dinâmicas e qualidade de vida locais; - parcerias, cujo estabelecimento é essencial para a existência de um clima de confiança e de cooperação entre os agentes do território; - inserção, sobre a forma como o turismo promove o desenvolvimento de novas empresas e atores; - acessibilidade, acerca dos níveis da procura de turismo por parte das populações envolvidas nos espaços considerados (SILVA; PERNA, 2005, p. 468).

Há de se considerar que iniciativas como o projeto Via Algarviana poderão promover uma crescente sensibilidade para temas que produzam melhorias na redução da perificidade regional e "[...] nas condições de base que influenciam a capacidade de fixação da população" (FREITAS, 2002, p. 13).

Desse modo, práticas, valores e instituições historicamente constituídas no destino turístico internacional Algarve poderão receber maior atenção no que concerne às condições de criação de pequenas iniciativas de investimentos privados, fortalecendo os níveis locais de emprego. Por último, a obra de Silva e Perna (2005) destaca a dimensão institucional, cuja mensuração deve incorporar critérios de avaliação sustentados em:

[...] participação, através de verificação da possibilidade de expressão junto dos governos e administrações dos diversos agentes locais; - transparência, tendo em vista o envolvimento equitativo das instituições e grupos participantes; - solidariedade, onde as instituições desempenham um papel central da preservação de valores para as gerações futuras; - tolerância, verificando de que forma as instituições são a garantia da expressão e valorização da diferença e inovação (SILVA; PERNA, 2005, p. 469).

O investimento turístico, ao dotar a região de infraestruturas destinadas ao acolhimento, à acessibilidade, à animação e à informação, entre outros aspectos, precisa forçosamente balizar o sentido e a dimensão dos gastos conforme critérios de organização territorial, tendo em vista a multiplicidade de atividades que se localizam nesse lugar. As cadeias hoteleiras apostam na certificação ambiental como uma maisvalia dos serviços oferecidos, capaz de distingui-los entre os iguais, além do sempre presente balanço financeiro dos investimentos (SILVA; PERNA, 2005).

Diante dessas constatações, Cândido (2003, p. 25) escreve em sua obra que o segmento do turismo, baseado na natureza, é conhecido como "[...] ecoturismo, turismo ecológico, turismo verde, turismo de aventura [...], turismo sustentável”. O mesmo autor comenta que a essência dos termos ora citados é a interpretação do ambiente, posto que a principal motivação de quem pratica essas atividades é a apreciação da natureza. 
Nesse contexto:

[...] as práticas de planeamento e gestão sustentável do turismo são factores de vital importância para a sustentabilidade dos lugares e a viabilidade do turismo. Se a actividade turística não for bem planeada, ela pode provocar a degradação da natureza, conflitos sociais e desorganização do sector empresarial prejudicando, deste modo, o ciclo de vida dos destinos turísticos. Por isso, o planeamento do turismo sustentável a nível regional deve levar em atenção o envolvimento de todos os actores do turismo. Só desta forma é que o planeamento minimizará os potenciais impactos negativos, maximizará os retornos económicos do destino e encorajará um maior envolvimento da comunidade receptora no turismo. (MARUJO; CARVALHO, 2010, p. 159).

Ao abarcar o turismo e o desafio da sustentabilidade, Matteucci (2003, p. 23) cita que essa deve ter a proposta de uma atividade diferenciada, “[...] sob a ótica de preservação/conservação da natureza/cultura, sendo essas finalidades sintetizadas dentro dos princípios da sustentabilidade, a palavra mágica que, presente, legitima e qualifica qualquer modalidade de usos, ações e atividades".

Ao analisar bibliograficamente as diferentes abordagens sobre turismo e o desafio da sustentabilidade, é possível afirmar que o crescimento de atividades como o pedestrianismo desenvolvido na região Algarve se deve, sobretudo, ao elevado interesse global por temas ambientais e culturais.

\section{PEDESTRIANISMO NA VIA ALGARVIANA E O TRABALHO DA ALMARGEM}

No senso comum, o pedestrianismo pode ser compreendido como algo que acontece espontaneamente, pela necessidade de deslocamento humano, dentro de um conjunto de ações e imaginários que constituem o cotidiano. Nesse sentido, a arte de caminhar é vista como um fio condutor para o entendimento da sociedade, uma vez que “[...] é na vida cotidiana que acontecem as verdadeiras criações, as ideias, os valores, os costumes. Os sentimentos expressam-se no cotidiano” (LEFEBVRE, 1991, p. 27).

Com base na obra de Cunha (2001), é possível conceituar o pedestrianismo como uma atividade (e até mesmo uma viagem de curta distância) provocada pelo desejo de ver coisas novas, de aumentar os conhecimentos, de conhecer as particularidades e culturas diferentes do passado e do presente. Nesse caso, segundo o 
mesmo autor, afirma-se que o interesse por paisagens historicamente preservadas foi, desde sempre, um dos mais importantes fatores de desenvolvimento de um turismo que se torna cada vez mais acentuado.

Conforme observações realizadas pelos elaboradores deste artigo, grande parte das atividades pedestres é realizada para destinos que dispõem de fatores ambientais e culturais notáveis, tais como recursos hídricos, parques nacionais, unidades de conservação, ruas e centros históricos, produtos regionais, festas tradicionais, culinária de paisagens locais, belezas cênicas - geológicas e geomorgológicas (geodiversidade), entre outros. De forma genérica:

[...] a geodiversidade representa os aspectos inanimados do Planeta Terra, não apenas aqueles ligados ao passado geológico, como os minerais, as rochas e os fósseis, mas também os processos que ocorrem atualmente. Geodiversidade é um termo muito recente, que começou a ser utilizado por geólogos e geomorfólogos no início da década de 1990, para descrever o meio abiótico (NASCIMENTO; SANTOS, 2013, p. 9).

Ainda de acordo com as observações realizadas pelos pesquisadores, em diversas paisagens do mundo caracterizadas pela riqueza cultural e de geodiversidade, o pedestrianismo se torna uma oferta complementar ao produto "turismo", contribuindo com o desenvolvimento econômico, ambiental e social de base local e regional. Assume-se relevância nos meios rurais e em pequenas vilas (FIGURA 2), se mostrando um produto específico, cheio de particularidades culturais e ambientais. Ademais, é uma atividade que depende de agências e associações de desenvolvimento local e regional.

Entende-se que a abordagem do turismo e do desafio da sustentabilidade, realizada anteriormente neste trabalho, contribui sobremaneira para enfatizar $o$ significado das paisagens e a relevância ambiental na manutenção do espaço vivido. Isso é feito a partir das experiências e descobertas pessoais e da dimensão simbólica da vida. 


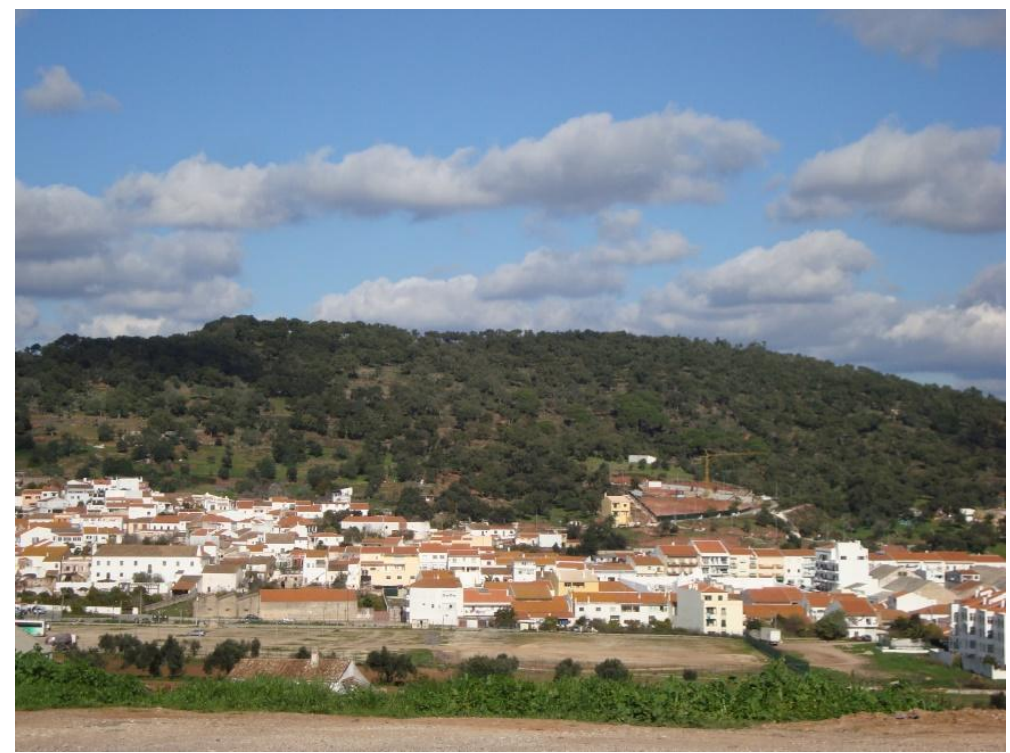

FIGURA 2 - VILA DE SÃO BARTOLOMEU DE MESSINES, NA REGIÃO SERRANA ALGARVIA.

FONTE: Jean Carlos Vieira Santos, 2014.

A partir disso, neste estudo se apresenta uma análise acerca do pedestrianismo, destacando a Via Algarviana e o trabalho da Almargem. O pedestrianismo e a observação da natureza no Algarve têm sido as atividades mais desenvolvidas por essa associação desde a sua criação, em 1988 (ALMARGEM, 2016).

Em 1995, iniciaram-se os preparativos para uma travessia do Algarve a pé, de forma a conhecer o interior da região e o seu elevado potencial para esse tipo de atividade (ALMARGEM, 2016). De acordo com Tovar e Carvalho (2011, p. 307), “[...] o desenvolvimento do pedestrianismo e dos percursos pedestres é relativamente recente em Portugal", apontando-se a década de 1990.

Na década de 1990 foi consolidada a criação da Via Algarviana. No momento da pesquisa, tal caminho se encontrava sinalizado no terreno com um conjunto de equipamentos e painéis de interpretação. Além desses materiais foram colocadas inúmeras pinturas em superfícies naturais, nomeadamente rochas, de forma a indicar o sentido do percurso e a distância que o caminhante se situava em relação a determinada povoação ou local.

Os painéis interpretativos estavam instalados no início e/ou final de cada setor e se destinavam a informar o viajante sobre sua localização, incluindo o patrimônio natural e cultural e os locais de hospedagem e alimentação disponíveis. Em cada comunidade houve a preocupação de aproximar o projeto Via Algarviana dos locais de 
maior interesse natural e cultural, bem como dos serviços ligados à atividade turística, a exemplo dos empreendimentos de turismo rural. (ALMARGEM, 2016).

A Almargem tem como objetivos principais: o estudo e a divulgação dos valores mais significativos dos patrimônios natural, histórico e cultural do Algarve; a defesa intransigente desses mesmos valores e a apresentação de propostas concretas para a sua recuperação e valorização; e a promoção de atividades que visem a um desenvolvimento local integrado e respeitador da natureza (ALMARGEM, 2016).

Torna-se relevante mencionar que a Almargem estava desenvolvendo habitualmente atividades bastante diversificadas que iam desde a execução de projetos de sensibilização ecológica e cultural até a organização de ações de descoberta e promoção da natureza e do mundo rural, passando pela produção de estudos e pareceres técnicos e científicos (ALMARGEM, 2016). Ainda, segundo consta na mesma fonte, procurava-se, também, manter uma vigilância e intervenção constante perante as ameaças e agressões que afetavam o ambiente e o patrimônio cultural do Algarve.

Como forma de perpetuar uma experiência, o trabalho da Almargem que traz um conteúdo de sustentabilidade deve ser analisado em seu contexto regional, pois é um elemento constitutivo de sujeitos envolvidos com as questões algarvias e as relações de aprendizado em diferentes contextos portugueses e globais. Durante os trabalhos de campo, pôde-se perceber que tal projeto de serviços aproximava sujeitos sensibilizados com a atividade turística, incorporando o apoio social aos lugares.

Diante disso, pode-se afirmar que o turismo e a busca pela conservação dos elementos naturais e culturais se colocam como um fenômeno civilizacional embasado em ações de ONGs, mas que, em suas contradições, envolvem o consumo de paisagens e territórios ao longo da Via Algarviana. De fato, sob o viés do desafio da sustentabilidade, o turismo deve ser visto "[...] no âmbito de um paradigma moderno de gestão e planejamento de pessoas" (COSTA et al., 2014, p. 13).

Por conseguinte, as ligações entre as ações da Almargem e os territórios, as paisagens, a região e os lugares:

[...] parecem-nos particularmente importantes no tecido das práticas turísticoculturais da sociedade contemporânea. É neste sentido que as novas cumplicidades entre turista/visitante e o lugar representam, para a sociedade contemporânea, um elo entre a tradição e a modernidade e, por isso, uma ligação em construção permanente. (CRAVIDÃO, 2014, p. 60). 
Diante dessa potencialidade espacial aberta ao turismo, são apontados outros olhares mais complexos que incluem a análise pautada na sustentabilidade sociocultural: "Las bases generadoras del turismo sostenible deben identificarse en pilares sólidos, que garanticen procesos continuados e integrales" (FAYOS-SOLÀ; JAFARI, 2009, p. 161). Isso leva a uma crescente motivação para preservar os valores patrimoniais e naturais de diferentes destinos turísticos.

Uma das características mais marcantes da relação entre turismo, natureza e cultura reside na experiência vivenciada na Via Algarviana, no destino turístico internacional Algarve, em Portugal. Nessa rota pedestre, os atrativos de diferentes territórios tornaram-se importantes para os planos de desenvolvimento econômico e de emprego, uma novidade induzida pelo turismo que incrementa não só a dimensão econômica, mas também as nuances social e cultural (ALMARGEM, 2016; VIA ALGARVIANA, 2016).

A experiência da atividade pedestre na Via Algarviana é uma componente de desenvolvimento do turismo no sul de Portugal que auxilia na diferenciação dos produtos de lugares variados que compõem o contexto regional. Nas primeiras décadas do século XXI, os deslocamentos a pé têm ganhado importância para a competividade do destino turístico internacional Algarve, impulsionando a conservação e valorização dos patrimônios natural e cultural (VIA ALGARVIANA, 2016).

Nesse entremeio, o pedestrianismo e a Via Algarviana podem se ligar à elaboração de novos projetos públicos e privados, a exemplo do trabalho em desenvolvimento da Almargem na cidade de Loulé. Podem-se destacar os argumentos de Trigo (2013, p. 139) para dizer que o trabalho da ONG supracitada exige condições especiais, “[...] atitudes e posturas sociais, culturais, estéticas e políticas que permitam uma diferenciação e uma marca".

Ao promover educação e novos conhecimentos, a reflexão a partir das ações da Almargem trouxe possibilidades multidisciplinares de discussões e análises fecundas, pois levou este trabalho ao cruzamento das relações ambientais por meio do pedestrianismo com o espaço algarvio. Nota-se que o projeto Via Algarviana não nasce por simples influência de seus interlocultores, mas por existir matéria-prima na região Algarve, sul de Portugal. 
Tovar e Carvalho (2011) lembram que a organização de passeios pedestres em Portugal não é exclusiva das empresas portuguesas, uma vez que há operadores estrangeiros que organizam este tipo de programas no país. Os autores comentam que existe um importante conjunto de operadores estrangeiros que estava vendendo férias de passeio pedestre em Portugal, essencialmente produtos que, pela forma como são apresentados, apelando à beleza da paisagem e riqueza natural, se enquadram na esfera do turismo de natureza. De acordo com Medina e Santamarina (2004, p. 42), o turismo de natureza se associa às atividades desenvolvidas em "[...] los bosques y espacios naturales $[\ldots] "$.

\section{CONSIDERAÇÕES FINAIS}

Ao discutir a relação do turismo com pedestrianismo como uma componente do turismo de natureza e cultural, uma lógica que marcou esse trabalho é a experiência desenvolvida na região Algarve e denominada como Via Algarviana. Ancorou-se na parceria com a Almargem, em que se identificaram perspectiva dinâmica e técnicas comerciais que estavam ligadas a uma linguagem contemporânea da atividade turística.

É preciso ressaltar, ainda, que o projeto da Almargem apresentado neste artigo aporta na vertente do desenvolvimento integrado da cultura e do meio ambiente no sul de Portugal. Logo, busca-se tecer relações vividas no tempo e espaço que estabelecem o cotidiano e se relacionam ao global por meio de conexões e redes a partir da atividade turística - isso é permeado pela busca do desenvolvimento integrado.

As discussões abordaram o pedestrianismo como uma componente do desenvolvimento integrado do turismo no destino turístico internacional Algarve, mostrando que, para a sua realização e concretização, são fundamentais a intervenção e a participação dos atores envolvidos e sensibilizados com a atividade turística. Esses agentes desempenham um papel central na dinâmica do turismo cultural e de natureza, a partir da criação e disponibilização de infraestruturas básicas e equipamentos de suporte, bem como nas parcerias desenvolvidas com os setores privado e público e as ONGs. 
Diante do objeto ora investigado, assevera-se que o pedestrianismo desenvolvido na Via Algarviana se afirma como mola dinamizadora de um turismo que também visa à qualidade de vida no sul de Portugal. Tal contexto é importante para que o turismo assuma a função de requalificador do território, apostando na diversificação de atividades voltadas para o meio ambiente e paisagens culturais e históricas que reúnem recursos de variadas ordens, o que permite executar políticas de ofertas complementares ao produto "sol e praia" na região Algarve.

Pode-se discorrer que a prática do pedestrianismo na Via Algarviana é uma tomada de consciência acerca da importância de uma gestão estratégica e planejada da Almargem que integra o turismo, a cultura e a natureza. Tal essência mostra que o destino turístico precisa abordar cuidadosamente os aspectos da natureza e cultura que estão ligados aos seus diferentes territórios, sendo responsáveis pelas visitas de turistas nacionais e estrangeiros.

Enfim, este trabalho, no que tange ao projeto da Almargem na Via Algarviana, trouxe reflexões e descobertas, mas também fez surgir várias ideias e aspirações. Nesse sentido, será necessário fazer uma nova leitura daqui a algum tempo, ou seja, avaliar as metas atingidas que foram colocadas em prática e o envolvimento contínuo entre as diversas entidades públicas de âmbito municipal e regional, de associações de desenvolvimento do turismo e de outros setores econômicos.

\section{REFERÊNCIAS}

ALMARGEM. Associação de Defesa do Patrimônio Cultural e Ambiental do Algarve. Quem somos. Disponível em:

$<$ http://almargem.org/siteantigo/index.php?option=com_content\&view=article\&id=17\& Itemid=22>. Acesso em: 23/06/2016.

CÂNDIDO, L. A. Turismo em áreas naturais protegidas. Caxias do Sul: EDUCS, 2003.

COSTA, C.; BRANDÃO, F.; COSTA, R.; BREDA, Z. Turismo nos países lusófonos: conhecimento, estratégia e territórios. Lisboa: Escolar, 2014.

CRAVIDÃO, F. Velho(s) território(s): novo(s) turismo(s). In: COSTA, C.; BRANDÃO, F.; COSTA, R.; BREDA, Z. Turismo nos países lusófonos: conhecimento, estratégia e territórios. Lisboa: Escolar, 2014. 
CUNHA, L. Introdução ao turismo. Lisboa: Editorial Verbo, 2001.

FAYOS-SOLÀ, E.; JAFARI, J. Cambio climático y turismo: realidad y ficción. Valencia: Publicaciones de la Universidad de Valencia, 2009.

FREITAS, M. Plano estratégico para as áreas de baixa densidade do Algarve. Faro: Comissão de Coordenação da Região Algarve, 2002.

IGP. Instituto Geográfico Português (2009). Disponível em: www.igeo.pt.

LEFEBVRE, H. A vida cotidiana no mundo moderno. São Paulo: Ática, 1991.

MARUJO, M. N.; CARVALHO, P. Turismo, planeamento e desenvolvimento sustentável. Revista Turismo \& Sociedade, v. 3, n. 2, p. 147-161, outubro de 2010.

MATTEUCCI, M. B. de A. Ecoturismo em Goiás - teoria e prática. In: ALMEIDA, M. G. de. Paradigmas do turismo. Goiânia: Alternativa, 2003.

MEDINA, N.; SANTAMARINA, J. Turismo de naturaleza en Cuba. Havana: Ediciones Unión, 2004.

NASCIMENTO, M. A. L. do; SANTOS, O. J. Geodiversidade na arte rupestre no Seridó Potiguar. Natal: IPHAN-RN, 2013.

RIBEIRO, O. Portugal - o Mediterrâneo e o Atlântico. 4. ed. Lisboa: Livraria Sá da Costa, 1986.

SANTOS, J. C. V. Região e destino turístico: sujeitos sensibilizados na geografia dos lugares. São Paulo: Allprint, 2013.

SANTOS, J. C. V.; SILVA, J. A. A arte da olaria no turismo da região Algarve, Portugal. Revista Turismo - Visão e Ação (UNIVALI), v. 17, n. 3, p. 658-690, dez. 2015.

SILVA, J. A.; PERNA, F. Turismo e desenvolvimento autossustentado. In: COSTA, José Silva (Coord.). Compêndio de economia regional. Coimbra: Gráfica de Coimbra; APDR, 2005.

TOVAR, Z.; CARVALHO, P. Percursos pedestres e turismo de passeio em Portugal. Revista Turismo \& Sociedade, v. 4, n. 2, p. 305-322, outubro de 2011.

TRIGO, L. G. G. A viagem: caminho e experiência. São Paulo: Aleph, 2013.

VIA ALAGARVIANA. O percurso. Disponível em:

<http://www.viaalgarviana.org/index.php/the-track/>. Acesso em: 23/06/2016.

Recebido em: 16-08-2016.

Aprovado em: 15-09-2016. 